\title{
Disease Profile and Death Pattern Among Children Admitted in a Medical College Hospital
}

\author{
M SHAMEEM HASAN ${ }^{1}$, SANAT KUMAR BARUA ${ }^{1}$, M NASIRUDDIN MAHMUD ${ }^{1}$, AHM KAMAL ${ }^{2}$, \\ M ENAYETULLAH ${ }^{1}$, M REZAUL KARIM $^{3}$
}

\begin{abstract}
Background: An understanding of epidemiological trend in hospital admissions, including diseases and death pattern, is critical for health care planning, appropriate resource allocation \& improving existing services facilities.

Objectives: To evaluate the disease and death pattern of children admitted in the department of Child Health, Chittagong Medical College Hospital (CMCH), Chittagong.

Materials and Methods: This was a retrospective study. The case records of all patients admitted in the department from Jan 1, 2008 to Dec 31, 2010 were analyzed.

Result: Total 38,692 children were admitted during this study period; among them total $1897(4.9 \%)$ patient died. Infant and under five age groups constitute $45.2 \%$ and $75.9 \%$ respectively, total admission whereas deaths from the same groups were $43.7 \%$ \& $79.3 \%$ respectively. Bronchopneumonia (22\%), acute watery diarrhea (15\%), hereditary hemolytic anemia (12\%), and bronchiolitis (10\%), topped the first four positions in each of the three years of admission. Septicemia and encephalitis, with a case fatality rate of $24 \%$ and $35 \%$ respectively, were found as top two causes of death. Highest case fatality rate was found in hepatic encephalopathy (54\%). Other common causes of death include meningitis (19\%), severe malaria (21\%), leukemia (22\%), severe malnutrition with complications (11\%), and congenital heart diseases (12\%)

Conclusion: Comprehensive evaluation of admission and death related findings of this study will help to determine possible gaps in patient care and planning for more effective case-management strategies.
\end{abstract}

Key words: Admission, Death, Chittagong Medical College Hospital (CMCH).

\section{Introduction}

Morbidity and mortality among children are merely estimated in developing countries, because of the difficulties in obtaining data accurately. Useful information on this regard can easily be obtained from periodic review of morbidity and mortality in medical institutions as it reflects what is occurring

1. Assistant Professor, Department of Child Health, Chittagong Medical College, Chittagong, Bangladesh.

2. Associate Professor, Department of Biochemistry, Southern Medical College Chittagong, Bangladesh.

3. Associate Professor and Head, Department of Child Health, Chittagong Medical College, Chittagong, Bangladesh.

Correspondence: Dr. Mohammad Shameem Hasan. email: dr.shamim_hasan@ymail.com in a community. ${ }^{1}$ Such understanding of epidemiological trend in hospital admissions is critical for health care planning and appropriate resource allocation ${ }^{2,3}$. Childhood mortality is a reliable indicator of health care facilities of a country and its development. ${ }^{4}$ Hospital death records statistics are considered reliable and used all over the world. ${ }^{5}$ Moreover; evaluation of characteristics of children who dies in hospitals gives an insight into main medical illness in children and measures to overcome those ${ }^{6}$. Therefore, review of such information help to draw attention to the pattern of childhood illness in the community. 
Almost one fourth children born in developing countries die before their fifth birthday, in sharp contrast to only $2 \%$ in developed countries ${ }^{7,8}$. More than one third of under five children die in neonatal period. In Bangladesh there has been shown a dramatic improvement in childhood death from 2007 to 2009 . The under-five mortality rate of 65 , Infant mortality rate (IMR) of 52 and neonatal mortality of around 71 has been changed to 52,41 , and 30 respectively in 20099,10 . The country is currently on target for achieving the MDG-4 relating to child mortality.

Chittagong, second biggest city and an administrative Division of Bangladesh, having a land area of 5283 SqKm ${ }^{9} .1000$ bedded Chittagong medical college hospital is serving the population of the surrounding six districts covering an area of $21988 \mathrm{sq} \mathrm{km}^{9}$ for its unique location. Analysis of admission \& death in this hospital should therefore give better evaluation of patients caring service of these region.

\section{Materials and Methods}

Study type: This was a retrospective observational study. Settings: Department of child Health, $\mathrm{CMCH}$; Chittagong, Bangladesh. Period: $1^{\text {st }}$ Jan 2008 to $31^{\text {st }}$ Dec 2010. Population: All the admitted children aged $>28$ days to 12 years (upper age limit for admission in pediatric ward), in the Department of Child Health, $\mathrm{CMCH}$ over a period of 3 years. Sample size: $38,692$. Exclusion criteria: Neonatal (up to 28 days) cases are managed in a separate unit under the same department, hence were excluded in this study. A patient who left the hospital after an admission of their own (Discharge on request or Discharge on risk bond), or left the hospital unnoticed (absconded), or was transferred to other discipline was also excluded from the study. Patient without adequate clinical records were also excluded from the study. This exclusion criterion was also set for those cases where final outcome remained unknown. Data Collection: Data was collected from hospital register, patient file records; death certificates. Data extracted from the records included total number of admissions and deaths, age, gender, month wise admission, income group of parents, mean duration of hospital stay before death, provisional diagnosis and cause of death. Final diagnosis was based on the final assessment by the managing unit. It was based on the presenting clinical features, with or without the results of laboratory tests. The cause of death as documented after weekly mortality reviews was considered as the final cause of death. Group comparison was done by Chi sq test. Descriptive statistics was used to analyze the obtained data.

\section{Results}

Over a span of three years, there were total 38,692 admissions and 1897 deaths showing $4.9 \%$ case fatality. A rise in the total number of patient admissions have been seen in 2010, but number of deaths remained almost same in all the three years. Average male female ratio on admission was 1.5:1. This gender distribution was found highly significant among admissions but found insignificant among those who succumbed. $93 \%$ of the admitted patient had their parental monthly income below taka 5000 per month.

All the patients were segregated into three age groups. This age wise distributions of patients in admissions and deaths were depicted in Figure-I \& Figure-ll. Among the admitted cases, Infants and Children from 1-5 years of age have represented $45.2 \%$ and $30.7 \%$ respectively. On the contrary, among the death cases, these age groups represented $43.7 \%$ and $35.6 \%$ respectively means total under five mortality was found $79.3 \%$ in the study.

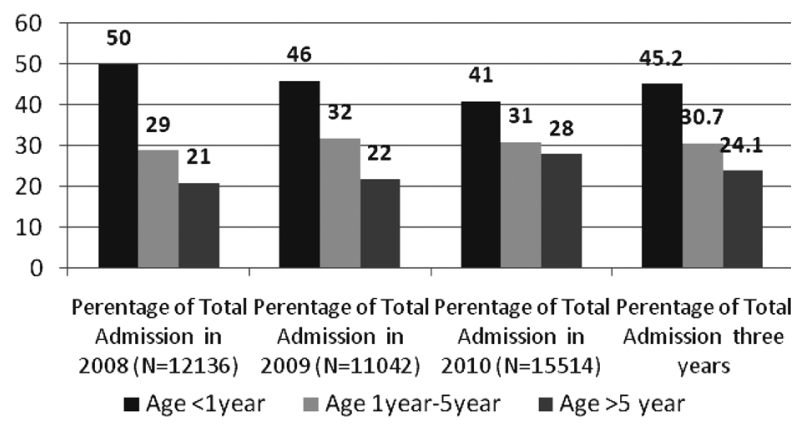

Fig.-1: Frequency distribution of the percentage of admissions.

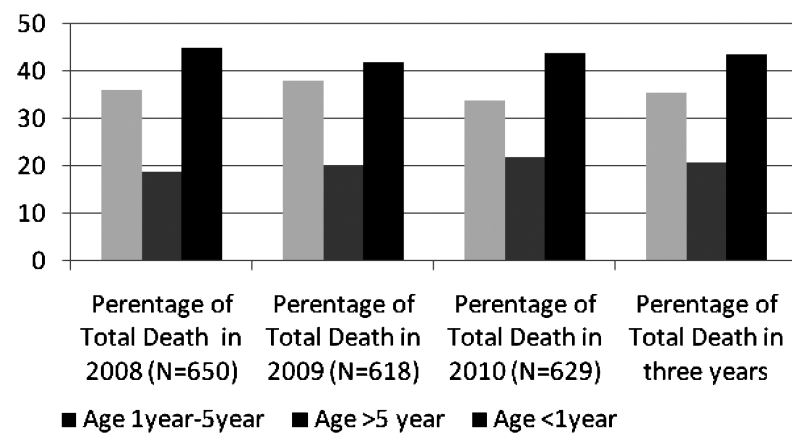

Fig.-2: Frequency distribution of the percentage of deaths.

Figure-III shows the basic data of total admissions \& Table-I shows deaths and the case fatality rate during the study period. Diseases and Deaths were arranged in order of frequency, showing the number and percentage of each of the diseases in individual year. Table-I also shows the summated number of 
admissions and deaths of a particular disease with their total percentage during the three year period.

Most frequent 16 diseases from admissions are shown in Figure-III and top 12 diseases causing deaths in Table-I. Besides these, diseases that had $<1 \%$ frequency were categorized as "Others". Among the admitted cases, Bronchopneumonia (22\%), Acute watery diarrhoea and a $(15 \%)$, Hereditary haemolytic anaemia (12\%) and Bronchiolitis (10\%), topped the

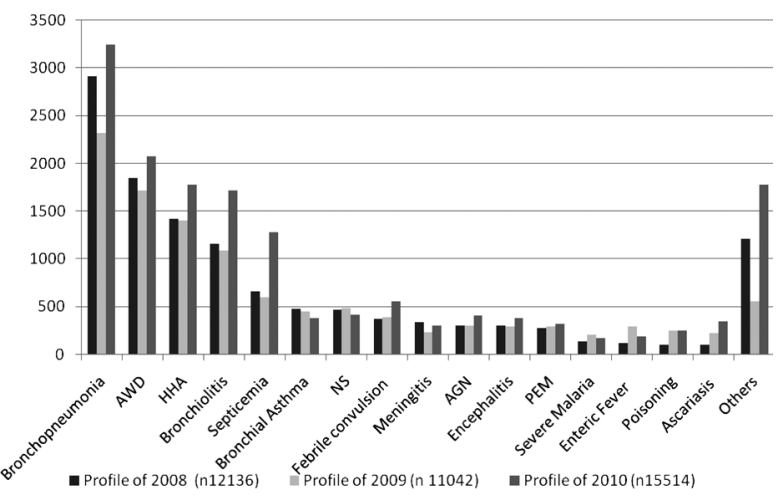

Fig.-3: Disease Profile of Admitted Patients ( $N=38,692)$ first four positions in each of the three years. They accounted for $60 \%$ of total admissions in the listed three years. Other diseases had varied frequency of distributions in both admission and death.

Seasonal variations were noticed in some of the diseases like Bronchopneumonia, Bronchiolitis, Asthma and AWD having two peaks in a year. Respiratory illness was more in September to December and in March-April period. Likewise, AWD also presented with two peaks, one in March-April and the other in Sep-December.

Septicemia and Encephalitis, was responsible for only $4.3 \%$ and $2.3 \%$ of the total admission but presented with a case fatality rate of $24 \%$ and $35 \%$ respectively in the study. They were found as common two causes of death in all the three years profile. In this study highest case fatality rate was found in Hepatic encephalopathy (54\%), though considering cause of death it represented $<2 \%$ of total death. We also found that $33.15 \%$ of the total admitted patient died within first 24 hours of admission.

Table-I

Most common diseases found among the total death cases. Arranged as per number of deaths. ${ }^{*}$ Figure within parenthesis indicates the percentage).

\begin{tabular}{|c|c|c|c|c|c|c|c|c|c|c|}
\hline \multirow[b]{3}{*}{ Disease } & \multicolumn{10}{|c|}{ Disease Profile of Death among Admitted Patients (Admission N= 38,692; Death $\mathrm{N}=1897$ ) } \\
\hline & \multicolumn{3}{|c|}{$\begin{array}{c}\text { Profile of } 2008 \\
\text { Total Admission } 12136 \\
\text { Total Death } 650\end{array}$} & \multicolumn{3}{|c|}{$\begin{array}{c}\text { Profile of } 2009 \\
\text { Total Admission } 11042 \\
\text { Total Death618 }\end{array}$} & \multicolumn{3}{|c|}{$\begin{array}{c}\text { Profile of } 2010 \\
\text { Total Admission } \\
\text { 15514Total Death } 629\end{array}$} & $\begin{array}{r}\text { Three Years } \\
\text { Total Death } \\
(\mathrm{N}=1897)\end{array}$ \\
\hline & $\begin{array}{l}\text { Total } \\
\text { admission } \\
\text { of a } \\
\text { disease }\end{array}$ & $\begin{array}{l}\text { Total death } \\
\text { from that } \\
\text { disease } \\
\text { ( } \% \text { of } \\
\text { total death) }\end{array}$ & $\begin{array}{l}\text { Case } \\
\text { fatality } \\
\text { rate } \\
(\%)\end{array}$ & $\begin{array}{c}\text { Total } \\
\text { admission } \\
\text { of a } \\
\text { disease }\end{array}$ & $\begin{array}{c}\text { Total death } \\
\text { from that } \\
\text { disease } \\
\text { (\% of } \\
\text { total death) }\end{array}$ & $\begin{array}{l}\text { Case } \\
\text { fatality } \\
\text { rate } \\
(\%)\end{array}$ & $\begin{array}{l}\text { Total } \\
\text { admission } \\
\text { of a } \\
\text { disease }\end{array}$ & $\begin{array}{l}\text { Total death } \\
\text { from that } \\
\text { disease } \\
\text { (\% of } \\
\text { total death) }\end{array}$ & $\begin{array}{c}\text { Case } \\
\text { fatality } \\
\text { rate } \\
(\%) \\
\end{array}$ & $\begin{array}{l}\text { e Total No of } \\
\text { ty Death of } \\
\text { a disease } \\
\text { (Mean case } \\
\text { fatality rate) }\end{array}$ \\
\hline Septicemia & 659 & $182(28)^{*}$ & 28 & 596 & $237(38)$ & 40 & 1275 & 185(29) & 15 & $604(24)$ \\
\hline Encephalitis & 300 & $100(16)$ & 33 & 290 & $100(16)$ & 34 & 372 & $141(22)$ & 38 & $341(35)$ \\
\hline Meningitis & 330 & $66(10)$ & 20 & 224 & $56(09)$ & 25 & 297 & $37(6)$ & 12 & $159(19)$ \\
\hline Bronchopneumonia & 2917 & $66(10)$ & 2 & 2319 & $85(14)$ & 4 & 3242 & $88(14)$ & 3 & $239(3)$ \\
\hline Severe Malaria & 131 & $50(8)$ & 38 & 202 & $25(4)$ & 12 & 168 & $30(5)$ & 18 & $105(21)$ \\
\hline PEM with complications & 269 & $33(5)$ & 13 & 288 & $29(5)$ & 10 & 315 & $31(5)$ & 10 & $93(11)$ \\
\hline Cong. Heart Disease & 94 & $20(3)$ & 21 & 105 & $06(1)$ & 6 & 129 & $13(1)$ & 10 & $39(12)$ \\
\hline Leukemia & 129 & $17(2)$ & 13 & 136 & $39(6)$ & 29 & 146 & $35(6)$ & 24 & $91(22)$ \\
\hline $\begin{array}{l}\text { Cerebral palsy with } \\
\text { complications }\end{array}$ & 65 & $14(2)$ & 21 & 71 & $05(1)$ & 7 & 132 & $11(1.75)$ & 8 & $30(11)$ \\
\hline $\begin{array}{l}\text { Bronchiolitis with } \\
\text { complications }\end{array}$ & 989 & $12(2)$ & 1.2 & 1089 & $08(1)$ & 1 & 1715 & $16(3)$ & 1 & $36(0.009)$ \\
\hline Heart Failure & 51 & $08(1)$ & 16 & 42 & $04(1)$ & 10 & 43 & $05(0.80)$ & 12 & $17(12.5)$ \\
\hline Hepatic encephalopathy & 13 & $07(1)$ & 53 & 18 & 09(1) & 50 & 30 & $17(3)$ & 57 & $33(54)$ \\
\hline Others & 6189 & $75(12)$ & 1.2 & 5662 & $15(3)$ & 0.2 & 7650 & $20(3)$ & 0.26 & $110(0.005)$ \\
\hline$\overline{\text { TOTAL }}$ & 12136 & $650(100)$ & - & 11042 & $618(100)$ & - & 15514 & $4 \quad 629(100)$ & & 1897 \\
\hline
\end{tabular}




\section{Discussion}

An increase in the number of the total admissions was noticed in 2010 in comparison to other two years. This is because of an outbreak in respiratory illness and AWD during that time. $\mathrm{CMCH}$ has the tendency of higher number of admissions in comparison to other tertiary level hospitals of the country for its unique location. There are other factors, including socioeconomic and parental education status and environmental factors which could influence admission patterns ${ }^{11}$.

On admission male female ratio of 1.5:1 was found in this study. Similar male preponderance is found other studies done in Nigeria ${ }^{1,2}$. This finding may reflect a gender bias in health seeking behavior regarding their children ${ }^{1}$. Alternatively, there may be epidemiological reasons for male susceptibility to infections or other conditions requiring admission ${ }^{3}$. Kanna $\mathrm{R}$ showed in his study that, girls have higher mortality due to sex differentiation in dietary intake, nutritional status and health care, ${ }^{12}$ but that was found statistically insignificant in this study. In this study $75.94 \%$ of the total admissions were from the under five age group, as in other study ${ }^{8}$.

Two-thirds (60\%) of the total admissions in all the three years were due to four common diseases like, Bronchopneumonia(22\%), AWD(15\%), HHA (12\%) and Bronchiolitis(10\%). Majority of admissions from Respiratory illness and AWD are also the common findings in other hospitals of the country. Hereditary hemolytic Anemia contributed a major portion (12\%) of total admissions could be due to multiple admissions of the same patients. A seasonal variation in some of the diseases with Bronchopneumonia, Bronchiolitis, Asthma and AWD having two peaks in a year in this study is consistent with global epidemiological trend.

Different studies carried out in hospitals in developing countries have revealed a fatality rate ranging from 5 to $14 \%{ }^{13}$. In India case fatality rate is $6.2 \%^{8}$ and $8.2 \%$ in Kenya ${ }^{14}$. Various mortality patterns ranging $2.6 \%$ $5.4 \%$ have been existed in different tertiary hospitals of Bangladesh. In this study mean mortality was found $4.9 \%$ which is consistent with those data. This higher mortality in our study could be due to the reflections of cumulative factors like higher number of moribund patients at admission, more patient load in context of logistics, late referral from remote centers, lack of ICU facilities at random, lack of isolation cubicle, and lack of round the clock laboratory facilities in this hospital .

Bangladesh is a malaria endemic country where total thirteen districts including Chittagong, are recognized as malaria endemic zone ${ }^{15}$. Therefore more malaria related admissions were expected in our admissions. Fortunately the surrounding primary and tertiary hospitals at rural areas can handle this moribund disease well; therefore they refer only the complicated cases to this tertiary level hospital, reflected by only $1 \%$ malarial admission.

ARI account for about $20 \%$ or more than two million of deaths, making it the leading cause of deaths in children aged less than five years ${ }^{16-18}$. In Bangladesh, 90,000 children $>1$ month and $<5$ years of age die from pneumonia every year ${ }^{19}$. Only $3 \%$ death was found in this study despite the highest number of admissions from Bronchopneumonia which may be due to early referral and parental awareness about respiratory distress. Globally $18 \%$ \& in Bangladesh $20 \%$ of childhood death occurs from AWD ${ }^{20}$. But our findings relating to diarrheal deaths are less in number, which may be due to the awareness \& increased use of Oral Rehydration Solution (ORS).

Infections have been studied to be responsible for nearly $70 \%$ of infant mortality ${ }^{21}$, and where pneumonia, meningitis and septicemia are the major contributors $^{22}$. In our study the leading causes of death, in order of frequencies, included Septicemia and Encephalitis which is similar to other centers of the country. Death from Hepatic encephalopathy showing highest case fatality rate $(54 \%)$ is also a sad back of our setting. Since Chittagong is an endemic zone, we face lot of near fatal patients from malaria each day reflected by the fifth common cause of the total mortality.

\section{Conclusion}

Findings of this study helps us to understand pediatric admission trend and death pattern of this institution, which are essential for health-sector planning, including effective case-management strategies. Comprehensive evaluation of admission and death related facts and findings of this study and then proper planning \& strengthening the community based programs may reduce hospital load and mortality as well as help to achieve the MDG 4 by 2015. 


\section{Refereces}

1. Obi JO. Morbidity and Mortality of Children Under Five Years Old in a Nigerian Hospital. Journal of the National Medical Association 1979; 71:24547.

2. George I.O, Alex-Hart B A. Frank-Briggs A.I. Mortality Pattern in Children: A Hospital Based Study in Nigeria. Int J Biomed Sci Dec 2009; 5:369-72.

3. C Eck, RB Pierre, IR Hambleton. Medical Pediatric Admission at the University Hospital of the West Indies: Issues for Future Planning. West Indian Med J 2006; 55:1: 340-45.

4. Anon. Pan American Health Organization. Preventable mortality: Indicator or target? Application in developing countries. Epidmiol Bull 1990; 11:1-9.

5. Indrayan A, Satyanarayana L. Measures of Mortality and Morbidity in Children. Indian Pediatrics 2000; 37:515-21.

6. Davis E, Waters E, Wake M. Population health and wellbeing: Identifying priority areas for Victorian children. Aust New Zealand Health Policy. 2005; 2:16.

7. Sukhbir K.Shahid." Pattern of Childhood Mortality In Sandakan Hospital, East Malaysia" The Internet Journal of Tropical Medicine 2008; 5:7982.

8. Chaturvedi P, Ayengar J, Chaturvedi D. Mortality Trends of Hospital Admission in a Rural Medical College Hospital with Special Emphasis on Infant Mortality. Indian Journal of Community Medicine 2004;29:10-12.

9. Bangladesh Demographic and Health Survey 2007. National Institute of Population Research and Training (NIPORT) Dhaka, Bangladesh. Mitra and Associates,Dhaka, Bangladesh.Macro International Calverton, Maryland USA. March 2009.

10. Unit for Children, UNICEF BANGLADESH statistics done in 2009 and updated in 2 March 2010. (www.unicef.org/infobycountry/ bangladesh_bangladesh_statistics).
11. Stewart M, Werneke U, MacFaul R, Taylor-Meek J, Smith HE, Smith IJ. Medical and social factors associated with the admission and discharge of acutely ill children. Arch Dis Child 1998; 79: 219224.

12. Kanna R, Kumar A, Vaghela JF . Community based retrospective study of sex in infant mortality in India. BMJ.2003;327:126.

13. Salam AKA. Common causes of Child mortality in Sana'a. Saudi Medical Journal.2005;26:111215.

14. Menge I, Esamai F, van Reken D, Anabwani G. Paediatric morbidity and mortality at the Eldoret District Hospital, Kenya. East Afr Med J. 1995 Mar; 72:165-9.

15. Haque U, Ahmed MS, Hossain S. Malaria Prevalence in Endemic Districts of Bangladesh. PLoS ONE www.plosone.org. 9 August 2009; Volume 4 Issue 8, e6737: 1-9.

16. World health report 2002: reducing risks, promoting health life. Geneva: World Health Organization; 2002. World Health Organization; p. 250.

17. Bulla , Hitze KL. Acute respiratory infections: a review. Bull World Health Organ. 1978;56:48198.

18. Black, Morris SS, Bryce J. Where and why are 10 million children dying every year? Lancet. 2003;361:2226-34.

19. Luby SP, Brooks WA, Saha SK, Sack D, and Robert F. Use of Multiple Surveillance Modalities to Assess the Epidemiology of Streptococcus pneumoniae Infection in Bangladesh Clinical Infectious Diseases 2009; 48:S97-102.

20. WHO Mortality Country Fact Sheet, 2006, Bangladesh

21. Deptt. of Preventive and social medicine, JIPMER. Report On The Baseline Health Survey Of Rural Health Center, Ramnathpuram, Villianur, Commune Pondicherry State. Pondicherry, JIPMER 1967; 9-54.

22. Dutt D, Srinivasa DK. Impact Of Maternal And Child Health Strategy On Child Survival Is A Rural Community Of Pondicherry. Indian Pediatr 1997; 34:785-92. 